\title{
EDITORIAL
}

\section{Claves para comprender la crisis financiera internacional}

\section{Consejo de Redacción}

Palabras clave: mercados financieros; crisis financiera; hipotecas "basura”; política monetaria.

Key words: financial markets; financial crisis; “junk” mortgages; monetary policy.

En nuestra era de la globalización, la economía mundial se caracteriza, entre otros fenómenos novedosos, por el enorme desarrollo de los intercambios financieros y monetarios que superan ampliamente a los intercambios de bienes y servicios reales. Una consecuencia de este fenómeno es la enorme influencia que lo que suceda en los mercados financieros tendrá sobre lo que ha dado en llamarse la economía real. Contrariamente a lo que pudiera pensarse, lo que ocurra en las finanzas internacionales no es algo que afecta sólo a una minoría de millonarios, grandes empresas y banqueros; repercute en la vida de millones de personas del mundo entero. Repercutirá directamente sobre todos los inversores (grandes y pequeños) y beneficiarios de créditos hipotecarios; y repercutirá indirectamente sobre todos, inversionistas o no, en la medida en que los ritmos de crecimiento de la economía real se verán rápidamente condicionados por estas perturbaciones financieras internacionales.

Ahora bien, como saben nuestros lectores, durante el segundo semestre del año 2007 se han producido una serie de acontecimientos alarmantes en dichos mercados financieros internacionales. Hemos pensado que podría ser de utilidad dedicar esta reflexión editorial del último número de 2007 de nuestra Revista a explicar lo sucedido y a esclarecer algunas de sus implicaciones. 
A lograr ese objetivo se dedican los apartados que componen este texto. En primer lugar respondemos sencillamente a la pregunta: ¿qué ha sucedido en los mercados financieros para que se llegue a hablar de "crisis"? A continuación nos preguntamos: ¿por qué han tenido lugar esos acontecimientos? En el apartado tercero describimos sumariamente cuáles han sido las actuaciones llevadas a cabo por los poderes públicos para responder a la crisis; es una manera de responder a la cuestión: ¿̇qué se puede hacer en estos casos? Luego nos preguntamos: ¿qué puede ocurrir a partir de ahora?', intentado formular la situación de las expectativas del inmediato futuro. Siguen unos breves comentarios acerca del impacto de esta crisis en España (apartado 5). Concluimos con unas consideraciones finales, de carácter ético, que nos permitan tomar postura ante la crisis estudiada.

\section{Descripción de la crisis}

Algunos hechos, que empiezan a manifestarse sobre todo en Estados Unidos a partir de junio de 2007, tienen que ver con la crisis que se avecina.

Comienzan a darse dificultades para vender las viviendas recién construidas. Incluso muchas de ellas se quedan sin vender. Como consecuencia de ello se produce un freno en la subida de los precios, que venía afectando al mercado inmobiliario; incluso asistimos a una cierta caída de los mismos.

Esta reducción del valor de la vivienda, unida al crecimiento de los tipos de interés, hace que algunos titulares de las hipotecas de alto riesgo ${ }^{2}$ no pueden atender sus compromisos crediticios.

Como resultado del fenómeno anterior, aumenta la morosidad y esto hace que los bancos se apresuren a reclamar la devolución de los créditos a corto plazo.

Ante esta insistencia de los bancos, los fondos de inversión libre, también llamados "hedge funds" o fondos de "gestión activa", se ven obligados a devolver los créditos

${ }^{1}$ Cerramos este texto en los primeros días de enero 2008.

2 También llamadas hipotecas "subprime" o hipotecas basura. Sus características son: el importe de las mismas es superior al $85 \%$ del valor de la vivienda hipotecada; los plazos de amortización son largos (hasta 40 años); las garantías sólidas aportadas por el prestatario son escasas; los tipos de interés son superiores a los del mercado (recordemos, sin embargo, que anteriormente los tipos de interés eran muy bajos). 
que tienen concedidos. Pero encuentran serias dificultades para vender sus valores en un mercado de muy escasa demanda. Algunos de estos fondos terminan por quebrar o se declaran en bancarrota ${ }^{3}$.

Bancos importantes, sobre todo de Estados Unidos, pero también de otros países (Reino Unido, Alemania, etc.), se encuentran ante graves problemas: descenso de beneficios e incluso pérdidas, dificultades de liquidez, etc. Las causas hay que buscarlas en algunas de las políticas que han seguido: suscripción de valores respaldados por hipotecas basura o de valores emitidos por fondos de inversión cubiertos con este tipo de hipotecas. Con frecuencia, el problema es que no se conoce cuál es el valor de las carteras de estas entidades.

También las sociedades de capital riesgo, que son entidades que captan recursos para invertirlos en nuevas empresas o en la ampliación de otras con aportaciones a su capital, se ven afectadas por estos hechos. Estas sociedades encuentran cada vez más dificultad para obtener los recursos que normalmente venían consiguiendo de las entidades bancarias (lo que se denomina operaciones apalancadas) o de los ahorradores. Esta falta de recursos les obliga a suspender la mayor parte de sus operaciones, lo que impide la puesta en marcha de algunos proyectos empresariales.

Ya en diciembre, han aparecido nuevos problemas: algunos bonos con garantía hipotecaria emitidos por bancos y que estaban en cartera de otras instituciones financieras han perdido valor, obligándolas a disminuir el importe de sus activos. Por parecidas razones, en las que no vamos a detenernos, esto ha afectado negativamente también a los bonos emitidos por entidades locales: municipios de USA.

Todos estos fenómenos no son independientes entre sí, sino que están estrechamente concatenados. Y la convergencia de todos ellos tiene como resultado una crisis de confianza. Los ahorradores no se atreven a invertir y las entidades bancarias se resisten a prestar, sobre todo en el mercado interbancario: en pocas palabras, nadie se fía de los mercados financieros. Esta crisis de confianza ha dado lugar a problemas de inestabilidad en los diferentes mercados. Veámoslo en detalle.

\footnotetext{
${ }^{3}$ Es el caso de dos grandes fondos del grupo estadounidense Bear Stearns, que quiebran en junio, sufriendo unas pérdidas equivalentes a 1.600 millones de euros.
} 


\section{I.I Los mercados interbancarios}

La importancia de estos mercados es difícil de exagerar. En ellos las entidades bancarias (bancos, cajas de ahorro y cooperativas de crédito) y, en menor medida, otras entidades financieras (fondos de inversión, fondos de pensiones, establecimientos financieros de crédito...) se prestan dinero a plazo corto, casi siempre, para atender a sus operaciones crediticias o de inversión. Para que funcionen con fluidez es preciso que exista dinero disponible en ellos (liquidez).

Todavía a principios de 2007 la liquidez era abundante, tanto en Estados Unidos como en la Unión Europea (UE). Incluso el Banco Central Europeo (BCE) veía en ella uno de los riesgos de inflación, porque su nivel era muy superior al de los objetivos fijados por dicha institución para un contexto de estabilidad.

Pero ya en los meses centrales de ese año se empieza a percibir una situación de falta de liquidez. Por una parte, nadie está dispuesto a prestar; por otra, los bancos reclaman la devolución de los créditos vencidos ${ }^{4}$. Resulta difícil y caro conseguir liquidez a más de un día. Es cierto que las entidades solventes consiguen fondos monetarios, pero se niegan a prestarlos, con lo cual el mercado se enrarece. Todo ello viene motivado porque no se conoce quién está implicado en la crisis y quién no.

Un ejemplo de la economía española puede ilustrar esta situación: el de las cajas de ahorro, que tradicionalmente han sido prestamistas netos en el mercado interbancario, sin embargo, durante la crisis llegaron a convertirse en prestatarios netos. Este estado de cosas es el que hace afirmar a algunos que el mercado se ha "secado".

Si las entidades disponen de menos recursos para prestar se ven obligadas a acudir a otras fuentes. La más frecuentada es la de los depósitos de la clientela, con dos consecuencias: que tienen que pagar más intereses y que tienen que disputarse los ahorradores. Esta lucha por los ahorradores es lo que se ha llamado la "guerra de pasivos".

\footnotetext{
${ }^{4}$ En el interbancario se suelen sustituir los créditos a corto plazo por otros también con corto vencimiento, asegurando la liquidez durante periodos relativamente largos.
} 
En conjunto, el sistema se hace menos eficiente: se necesita más liquidez para mantener la misma actividad, pero precisamente lo que escasea es la liquidez ${ }^{5}$. Los fondos de inversión o de pensiones tienen mayor dificultad para conseguir recursos en este mercado enrarecido, e incluso pierden patrimonio, lo que puede crearles nuevos problemas.

Visto ya con un poco de perspectiva, se puede decir que el principal problema de la crisis es la falta de liquidez, por lo que el comportamiento del propio sistema está impidiendo una pronta solución. Se duda, sin embargo, si esta crisis de liquidez oculta un problema de solvencia, pero para esto no hay una respuesta clara.

\section{I.2 Los mercados bursátiles y de renta fija}

En agosto las bolsas de Estados Unidos, e inmediatamente después, del resto del mundo experimentaron caídas profundas. ¿Cómo explicar estas caídas?

Ante todo, las subidas de los tipos de interés presionó a la baja las cotizaciones, al desviarse parte de los recursos y disminuir la demanda de títulos bursátiles. Además, para hacer frente a los problemas de los "hedge funds", muchos se vieron obligados a vender títulos de sus carteras. Ante la dificultad para obtener créditos, algunas empresas no financieras optaron por buscar recursos a través de emisiones de capital. A la reducción de la demanda ya señalada se une ahora un aumento de la oferta de valores de renta variable. Este desequilibrio sólo sirve para que los ahorradores se retraigan aún más (reduzcan su demanda) ante el temor de sufrir pérdidas en el mercado. La caída de las cotizaciones bursátiles queda así más que explicada.

Pero no todos los títulos ven reducirse su valor bursátil en las mismas proporciones. La caída es mayor en los bancos afectados por la crisis, y también en las sociedades inmobiliarias y en las empresas constructoras.

También los mercados de valores de renta fija se han deprimido. La crisis de confianza ha afectado sobre todo a los valores cubiertos con hipotecas, no sólo con hipotecas "basura", ante los que se resisten los potenciales compradores. Los ahorradores se han dirigido a inversiones más líquidas o más seguras (deuda pública, por ejemplo).

\footnotetext{
${ }^{5}$ Esto podría llevar a que los ahorradores mantuviesen una mayor tesorería por desconfianza del sistema ("guardar en el calcetín"). Esta práctica no se ha dado hasta ahora más que en algún caso (por ejemplo el del Northen Rock británico), pero no se ha generalizado.
} 
Inicialmente, el escaso diferencial de la contratación de la deuda privada sobre la pública también ha reducido la demanda de aquélla; todo lo cual ha determinado una reducción notable de la contratación de la deuda privadá.

En resumen, la caída de las bolsas se generaliza_Y, al estar todas interconectadas, dicha caída se extiende por todo el mundo. La crisis comienza a dejarse sentir incluso en los países que no estaban inicialmente involucrados en ella.

Es cierto que, posteriormente, las bolsas se han recuperado. Pero sólo en parte. De ningún modo han vuelto a alcanzar los niveles anteriores al comienzo de la crisis. Además al mismo tiempo la volatilidad (subidas y bajadas sucesivas de las cotizaciones) se ha elevado de forma intensa. Hay que recordar que esta volatilidad determina una gran incertidumbre sobre el precio de mercado de los valores.

\section{I.3 Los mercados de divisas}

Aquí el factor determinante ha sido la depreciación del dólar. Los motivos son fáciles de comprender. Entre ellos: la quiebra de algunos fondos de inversión de Estados Unidos, las pérdidas sufridas por algunos bancos de ese país, la caída de su bolsa, etc. La crisis de confianza resultante ha reducido la demanda de dólares para invertir en aquel país. Si ya hacía cinco años que el dólar venía perdiendo valor, su depreciación se ha acelerado ante estas nuevas circunstancias concurrentes.

Como es obvio la depreciación de una moneda significa que otra $u$ otras se aprecian. En nuestro caso, la apreciación ha afectado sobre todo al euro y a la libra esterlina. El yuan de China no podía apreciarse porque tiene un cambio casi fijo. Tampoco el yen japonés, ya que la economía japonesa parte de una situación negativa (aunque va mejorando), por lo que resulta muy difícil que se pueda apreciar. Sólo el euro y, en menor medida, la libra esterlina, se han apreciado sensiblemente como contrapartida de la caída del dólar.

Hay que recordar que esta trayectoria de la cotización del dólar favorece las exportaciones de Estados Unidos. Pero ni aún así está logrando este país eliminar su enorme déficit exterior. Y la financiación del mismo encuentra cada vez más dificultades en las condiciones actuales.

\footnotetext{
${ }^{6}$ La bajada de la contratación reduce el precio de los valores lo que da lugar a un aumento de su rentabilidad. Esto no ha afectado demasiado a la deuda pública pero sí ha encarecido las nuevas emisiones de deuda privada; nuevo aspecto negativo de las finanzas.
} 
Como se ve, la crisis financiera ha convulsionado también los mercados de divisas. Pero el comportamiento de éstos depende sobre todo de factores ajenos a los mercados financieros. Volveremos más adelante sobre esta cuestión.

Vinculado a la crisis financiera, aunque dependiendo también de otros factores, estamos asistiendo a una cierta huida respecto al dólar. Muchos países están reduciendo sus reservas de la moneda norteamericana y aumentando su tenencia de euros ${ }^{7}$. Puede decirse que el carácter del dólar como moneda refugio ha desaparecido, pero no es igualmente exacto afirmar que el euro le haya sustituido en ese papel. El dinero está buscando otros activos como refugio: como sucede siempre en las situaciones de crisis, este activo está siendo el oro, lo que está elevando su precio en el mercado. Por una razón semejante están aumentando igualmente los precios de muchas materias primas.

\section{Las causas de la crisis}

La causa directa de esta crisis hay que buscarla en el "boom" hipotecario que se ha desencadenado como medio para financiar el sector de construcción de viviendas. En Estados Unidos y en otros muchos países se ha venido construyendo de forma acelerada, lo que ha disparado los precios de la vivienda, ya que la demanda crece continuamente, no sólo por la necesidad de la vivienda misma, sino además por razones financieras y especulativas. Con objeto de facilitar la compra de viviendas se concedieron créditos hipotecarios en condiciones muy favorables, como la única manera de mantener el ritmo de construcción. El endeudamiento por parte de los compradores se vio apoyado por el bajo nivel de los tipos de interés oficiales, que permite unas tasas reales de interés (el interés menos la inflación) nulos, de forma que el comprador piensa que el crédito no le cuesta nada en términos de intereses a pagar por él. Se genera así lo que en los mercados llaman una "burbuja inmobiliaria", es decir un proceso de subidas de precios de un determinado bien (en este caso, la vivienda) que no corresponde a una situación de equilibrio en el mercado.

\footnotetext{
7 Entre los países que están reduciendo sus reservas en dólares están Kuwait, Venezuela, Irán, Rusia, Noruega y, en menor medida, China. Otros países de la OPEP (Organización de Países Productores de Petróleo) no se atreven a seguir esta política por temor a sus efectos desestabilizadores.
} 
Este "boom" hipotecario se facilitó gracias al comportamiento de los mercados financieros, donde se generalizó la práctica de la llamada titulización de créditos ${ }^{8}$. Entre los créditos cedidos por los bancos se incluían las hipotecas de alto riesgo, mezclados con otros créditos hipotecarios de mejor calidad, lo que podía hacer pensar que el riesgo disminuía o se diluía totalmente. Los valores de titulización resultantes (los emitidos por los fondos a los que los bancos cedían sus créditos) fueron suscritos por los ahorradores, por los fondos de inversión y por los fondos de pensiones. Muchos de éstos los revendieron, a su vez, a otras entidades financieras. De este modo tales valores se fueron extendiendo por todo el mundo, hasta el punto que nadie puede saber quiénes son sus poseedores últimos.

De todos modos, estas operaciones financieras se realizaron principalmente en Estados Unidos y, sólo en menor medida, en otros países. Y fueron acompañadas y favorecidas por la práctica de las agencias de valoración o "rating", que calificaban muy positivamente estos valores, lo que generó una gran confianza en los mismos. Hubo que esperar a junio de 2007 para que dichas agencias empezaran a rebajar la calificación y, consecuentemente, el mercado a desconfiar de esos valores. Esta actuación de las agencias ha sido luego muy criticada, cuando se ha visto cuáles han sido sus efectos en los mercados. Y se ha criticado de ellas sobre todo la oscuridad de sus prácticas de evaluación. Esta opinión cada vez más negativa sobre tales instituciones se ha reflejado incluso sobre sus cotizaciones.

En el fondo hay en todo esto un problema de permisividad: se ha tolerado que el sistema financiero actuara sin ningún freno o limitación, sin normas que regularan su funcionamiento, con absoluta libertad. Ni siquiera los supervisores, que son instituciones cuya responsabilidad es cuidar del buen comportamiento de las entidades financieras, lo han impedido?. Esta permisividad ha sido casi total en Estados Unidos. ¿̇Está ahí una explicación de la buena marcha de la economía estadounidense en ese periodo? Lo que sin duda está es la explicación de que haya sido precisamente en ese país donde la crisis se inició.

\footnotetext{
${ }^{8}$ La titulización consiste en que un banco cede los créditos (hipotecarios o no hipotecarios) de su activo a un fondo de titulización que emite valores y con los recursos obtenidos paga al banco, el cual concede nuevos créditos; el riesgo y los intereses de la hipoteca pasan al fondo de titulización, mientras que el banco retiene las comisiones; de esta forma todos ganan. Aunque no pretendemos culpabilizar a nadie, quizás tenga interés recordar que la titulización de las hipotecas "subprime" fue "inventada" por cinco agentes de los bancos Deutsche Bank, Goldman Sachs, Citigroup, J.P. Morgan y Bear Stearns en Wall Street. ¿̇Hay responsables?
}

' Un ejemplo, las sociedades de capital riesgo que, como hemos visto, realizan en gran parte operaciones a crédito, crean también inestabilidad y sin embargo ha habido una ausencia, en general, de control de las mismas, sin que haya existido una normativa reclamada por las propias sociedades. 
Téngase en cuenta por fin que estamos hablando de unos mercados que son muy vulnerables. Por eso en cuanto se produce un frenazo en la actividad constructora, todos esos mercados que se han desarrollado al amparo del "boom" inmobiliario empiezan a dar síntomas de crisis y terminan viniéndose abajo -como hemos descrito en el apartado anterior- desatando además la desconfianza de todos.

En resumen, la secuencia de hechos que configuran esto que hemos llamado la causa más coyuntural de la crisis sería la siguiente: todo surge con la "burbuja" inmobiliaria; ésta se desarrolla gracias a unas prácticas financieras poco transparentes, que ocultan los riesgos de esas operaciones; estas prácticas son permitidas gracias a la actuación de unas agencias de valoración que no actúan correctamente; falta, por consiguiente, una supervisión adecuada que encauce las actividades de un mercado libre.

Pero existe además un problema estructural que tiene cierta relación con la crisis que analizamos y que se ha manifestado en los mercados de divisas. Su origen se encuentra en el déficit exterior estadounidense que, en parte, está provocado por sus gastos militares. Pero lo que ningún gobierno se puede permitir, un déficit exterior en continuo crecimiento y fuera de control, es posible en los Estados Unidos por ser su moneda el principal componente de las reservas internacionales.

En efecto, los acuerdos de Bretton Woods (1944), que pusieron a punto el sistema monetario internacional hoy vigente, convirtieron el dólar en la moneda internacional a partir de un compromiso multilateral: todos los países se comprometían a aceptar esta moneda como medio normal de pago y a mantener un tipo de cambio fijo con el dólar, a cambio de que el gobierno norteamericano garantizase la convertibilidad de los dólares en oro. En estas condiciones, Estados Unidos pueden financiar sus déficits exteriores con emisiones de valores suscritos por los bancos centrales (como se ha indicado anteriormente uno de los principales acreedores es el banco central chino).

Es cierto que el sistema de Bretton Woods hizo crisis en 1971 cuando el gobierno norteamericano renunció a mantener el compromiso de la convertibilidad. Desde entonces los gobiernos de los restantes países comenzaron a interpretar con mucha flexibilidad sus compromisos en relación con los tipos de cambio de sus monedas. Pero el dólar siguió siendo el medio internacional de pago a falta de otro mejor. Por eso Estados Unidos pueden seguir tolerando fuertes déficits exteriores, aunque ahora lo hagan con unos mercados de divisas mucho más inestables. Quizás el efecto más notable de esta inestabilidad es la depreciación que ha sufrido el dólar en estos últimos cinco años. 
La depreciación reciente del dólar no ha sido suficiente par eliminar los déficits exteriores de Estados Unidos, pero han incrementado la competitividad de sus exportaciones. Como además la depreciación del dólar se ha hecho a costa del euro (casi la única moneda que, como ya dijimos, se ha apreciado en este mismo periodo), ha sido la Unión Europea la que ha perdido competitividad. Mientras tanto, China, que mantiene un tipo de cambio ficticio para su moneda, se ha visto beneficiada con fuertes superávits exteriores: en efecto, al ser este tipo de cambio inferior al que correspondería a una balanza de pagos en equilibrio, las exportaciones desde China se ven favorecidas, y frenadas sus importaciones.

La persistencia de los déficits exteriores norteamericanos ha tenido otro efecto: una creciente desconfianza en el "billete verde". Sin embargo, los bancos centrales no se atreven a eliminar sus reservas en dólares, al menos en su totalidad, para evitar una catástrofe económica de alcance mundial ${ }^{10}$. El resultado de todo esto no puede sino esa gran inestabilidad y volatilidad que caracteriza hoy a los mercados de divisas ${ }^{11}$.

Como se ve, se entrelazan dos procesos diferentes que se refuerzan mutuamente: como indicamos anteriormente, la crisis financiera ha afectado también a los mercados de divisas; a su vez la financiación del déficit norteamericano ha contribuido a agravar también la crisis financiera.

\section{Actuaciones políticas}

Ante una crisis de las dimensiones descritas sería de esperar algún tipo de intervención de los poderes públicos. Pero esto es difícil de encajar en unos mercados donde la libertad es como un postulado que nadie se atreve a discutir. Tal es el caso de los mercados financieros, presentados como el modelo más acabado de unas instituciones económicas donde reina el principio de la libertad.

\footnotetext{
${ }^{10}$ Algunos países que detentan grandes cantidades de reservas en dólares han comenzado a invertir los recursos de los fondos soberanos (deuda pública, sobre todo) en acciones de grandes empresas estadounidenses. Estas operaciones tienen un lado positivo: evitan la caída del dólar y estabilizan los mercados de divisas. Pero, si se generalizasen, tendrían un resultado de mayor calado: venta de una parte importante de la economía americana a otros países.

${ }^{11}$ Las reservas están constituidas en gran parte por deuda pública norteamericana; de aquí que la elevada deuda de Estados Unidos, privada y pública, provoca una intensa inestabilidad financiera.
} 
Con todo, algunas intervenciones públicas se han producido, por parte de los bancos centrales o de los organismos supervisores, o directamente por los gobiernos.

Los bancos centrales son organismos públicos, pero autónomos respecto a los gobiernos, con objeto de que puedan desempeñar eficazmente su función. Su intervención en los mercados se vale de la política monetaria, que consiste esencialmente en proporcionar (o retirar) liquidez en los mercados monetarios fijando unos tipos de interés, que llamamos tipos oficiales, los cuales, a su vez, afectan a las tasas de todos los mercados financieros.

Durante el "boom" hipotecario los bancos centrales fueron demasiado permisivos proporcionando unos volúmenes de liquidez que hicieron posible la "burbuja financiera". Cuando estalló la crisis y paradójicamente la liquidez se vuelve escasa, los bancos centrales facilitaron recursos a las entidades bancarias para paliar la crisis de liquidez, pero sin modificar los tipos oficiales. Concretamente, el Banco Central Europeo fue el más activo inyectando 200 mil millones de euros. La Reserva Federal Americana (FED) y el Banco de Inglaterra también aportaron recursos, aunque de forma más moderada. Sólo más tarde la FED se decidió a actuar sobre los tipos de interés: lo hizo bajándolos, mientras que el BCE optó por mantenerlos. Posteriormente, varios grandes bancos centrales: BCE, FED, Banco de Inglaterra, Banco de Canadá y Banco Nacional Suizo han decidido actuar conjuntamente en los mercados monetarios; esta política ha sido acertada, como se demuestra por la reducción del tipo de interés del interbancario (el EURIBOR).

Esta política de inyección de liquidez, unida a la elevación de los precios de los crudos y de otras materias primas, puede crear tensiones inflacionistas al mismo tiempo que puede impulsar la demanda. Si la inflación llegase a "desbocarse", no habría más remedio que actuar elevando los tipos oficiales, lo que terminaría perjudicando al crecimiento.

En cuanto a los supervisores (que no siempre son los mismos bancos centrales), evidentemente su función es prevenir los problemas a través del control de las entidades. Puede decirse que en determinados casos han cubierto esta función de forma satisfactoria. Pero ciertamente no en otros, en los que han permitido operaciones y prácticas poco ortodoxas: es lo que ha ocurrido sobre todo en Estados Unidos. La Reserva Federal está ahora dando directrices a las entidades financieras para que no concedan créditos sin las garantías suficientes. ¡Más vale tarde que nunca!

Los gobiernos, por su parte, sólo han intervenido en algunos aspectos puntuales. Citamos sólo tres ejemplos: el gobierno del Reino Unido amplió la cobertura del 
Fondo de Garantía de Depósitos para paliar los problemas del Northern Rock; el gobierno estadounidense está negociando ahora con la banca la congelación de la cuota de las hipotecas de alto riesgo para evitar los impagos de las citadas cuotas; el gobierno de la India llevó a cabo un control de los "hedge funds" para reducir la especulación, lo que redujo considerablemente los efectos de la crisis en este país.

Estas escasas actuaciones responden a la idea, hoy tan difundida, de que los gobiernos no pueden interferir en la marcha de los mercados. Por eso su papel en la corrección de la crisis ha sido irrelevante. Y, sin embargo, los ejemplos citados, especialmente del gobierno indio, muestra que incluso intervenciones puntuales pueden tener efectos positivos sobre las crisis que genera el mundo económico y financiero. Por todo esto, se ha llegado a afirmar que existe una responsabilidad de las autoridades americanas por su ausencia de control de los mercados.

\section{Las expectativas sobre el comportamiento económico mundial}

¿Qué se puede esperar en estos momentos? ¿Podemos decir que la crisis ya tocó fondo y las cosas tienden a volver a la normalidad? $\dot{i}$ Cabe esperar que los mercados se estabilicen? ¿Qué efectos tendrá todo lo descrito sobre la economía real?

\section{I Las expectativas financieras}

La mayor parte de los expertos no son optimistas: mantienen que las turbulencias continuarán durante $2008^{12}$. Este pesimismo encuentra su fundamento en algunos fenómenos recientes:

Diversos bancos de Estados Unidos y del Reino Unido han presentado ya unos malos resultados. Y los cálculos que se hacen para el futuro inmediato no son esperanzadores: el quebranto para el conjunto de la banca durante los tres próximos años se estima en unos 275 mil millones de euros; algunos expertos llegan a hablar de 400 ó 500 mil millones de euros. Naturalmente estas pérdidas, sobre todo en la medida en que se hacen efectivas y son reconocidas, influyen sobre las cotizaciones en bolsa de dichas entidades bancarias.

\footnotetext{
${ }^{12}$ Entre otros, lo indican el gobernador del Banco de Inglaterra, la agencia de calificación Standard \& Poor's, y el propio Rodrigo Rato, antes de dejar el Fondo Monetario Internacional.
} 
La crisis de liquidez ha vuelto a aparecer, no sólo en el mundo anglosajón. Como respuesta a ella, el BCE ha decidido inyectar de nuevo liquidez en el interbancario.

Como consecuencia de lo anterior, la prima de riesgo (diferencia entre el tipo de interés de las emisiones de valores privados y el de la deuda pública) se ha elevado hasta cifras que no se conocían en los mercados financieros. También se ha elevado la evaluación del riesgo de las operaciones crediticias, lo que va unido a un endurecimiento de sus condiciones.

La citada crisis de liquidez ha paralizado los mercados de deuda: las emisiones privadas encuentran dificultades o simplemente no se realizan, y los mercados secundarios de deuda pública están también paralizados.

Los malos resultados de los fondos de inversión se han extendido por todo el mundo. De forma inesperada los que invierten en China han presentado las pérdidas más elevadas.

Muchas entidades financieras están tardando en confesar cuánto dinero han perdido, lo que determina que la solución de la crisis se demore. En este sentido, recordemos que la FED está concediendo créditos a los bancos manteniendo el anonimato de los prestatarios. Esto que puede ser una medida prudente, contribuye, sin duda, a esa oscuridad que prolonga la duración de la crisis.

Pero no todos los expertos son igualmente pesimistas. También hay algunas opiniones positivas, pero son menos numerosas. Creen que la crisis ha pasado ya o que se resolverá en un semestre.

En lo que sí están de acuerdo casi todos los expertos es en que las dificultades para el sistema bancario europeo serán menos importantes, ya que, en general, la economía europea tiene más capacidad para afrontar estos problemas.

Merece una atención especial el caso de los mercados bursátiles. Paradójicamente, mantienen en general una tendencia creciente, pero acompañada de esa elevada volatilidad, que ya hemos citado. Hemos asistido a jornadas muy negativas, que han coincido con los momentos en que se conocían problemas graves de los mercados; pero pronto se ha producido la recuperación y se ha vuelto a tendencias alcistas. Turbulencias de este tipo son de esperar durante 2008. Lo que no se prevé es un "crack" bursátil.

Como se ha indicado anteriormente, el comportamiento de las cotizaciones de las monedas es otra fuente de incertidumbre. Por un lado, se teme un desplome del 
dólar e incluso del euro frente a las monedas asiáticas. Por otro, se espera que se produzca un cambio de tendencia de la cotización del dólar, en un sentido más positivo. Las expectativas no pueden ser más confusas.

Anteriormente, hemos aludido a la participación de financieros asiáticos en el capital de las grandes instituciones financieras, a veces con fondos "soberanos", es decir de la cartera de entidades públicas. Parece que esta política empresarial se va a generalizar en el futuro, lo que ha llevado a la Comisión Europea a establecer unas directrices para supervisarlas. ¡Cómo vemos a veces las instituciones públicas intervienen en los mercados! ${ }^{13}$

\subsection{Los efectos sobre la economía real}

En estos momentos se acepta de forma general que la crisis financiera tendrá un impacto negativo sobre la economía mundial. Ante todo, se traducirá en un menor crecimiento para 2008. En este sentido todas las previsiones sobre evolución del PIB han sido retocadas a la baja por el FMI. Para la economía norteamericana el "retoque" es de un punto, con lo que el aumento del PIB quedaría en el 1,9\%. Para la economía mundial la previsión de crecimiento en 2008 se establece en un $4,8 \%$.

El efecto de la crisis financiera sobre la economía mundial será el de una desaceleración generalizada. Pero no afectará a todas las economías por igual. Concretamente, se considera que su efecto sobre los países emergentes será menor: eso permitirá a estos países mantener todavía un alto crecimiento, aunque será inferior a 2007.

Pero esta desaceleración del crecimiento no vendrá causada sólo por la crisis financiera. Hay que mencionar otras causas: el freno de la actividad constructora, el aumento de los precios de los crudos, las turbulencias de los mercados de divisas, las tensiones geopolíticas (Pakistán, Oriente Medio, etc.), entre otras. Tampoco hay que olvidar el riesgo de una inflación en China, que afectaría negativamente a las economías desarrolladas, como ya afectó a todo Occidente la deflación que sufrió dicha economía hace unos años, sobre todo porque los productos occidentales sufrieron una fuerte competencia de los producidos en China que eran mucho más baratos.

\footnotetext{
${ }^{13}$ Refiriéndonos a España, hay un rumor de que un importante financiero indio quiere participar en un banco español, quizás el BBVA o el Banco Popular.
} 
En el caso de Estados Unidos, donde la crisis financiera ha sido más aguda, se espera un descenso del consumo y riesgos inflacionistas. Se discute, además, si la economía norteamericana podría entrar en recesión. Las opiniones y previsiones han ido variando: en agosto y septiembre se negaba la posibilidad de dicha recesión, pero posteriormente se impone la idea de que una situación recesiva en este país no podría excluirse. En estas previsiones se deben tener muy en cuenta los posibles efectos de una caída profunda del dólar o de una conversión masiva de las reservas en dólares en otras monedas, circunstancias ambas que no son impensables.

Las expectativas sobre la economía de la Unión Europea, sobre todo en la eurozona, son algo diferentes. Se espera un freno de la demanda interior, y también de la exterior a causa de la fortaleza del euro. Ahora bien, esta reducción de la demanda podría contribuir a aliviar las presiones inflacionistas, aunque no es de esperar que las elimine del todo.

Lo que es claro es que estamos ante un conjunto de causas que actúan de forma interrelacionada y que no son en modo alguno independientes ni pueden reducirse sólo a las exclusivamente financieras. Esta complejidad de causas es un factor más de incertidumbre. Por eso el comportamiento económico durante 2008 está rodeado de profundas incertidumbres e interrogantes.

\section{Efectos sobre los mercados financieros españoles y sobre la economía española en general}

En un mundo tan interdependiente y globalizado, ninguna economía puede entenderse de forma aislada. Las tendencias, positivas o negativas, de la economía mundial dejan su huella en las de todas las naciones. Evidentemente, la economía española no podía mantenerse al margen de la crisis de estos meses. Sin embargo, presenta algunos aspectos diferenciadores, que sería interesante destacar. Analizaremos en primer lugar lo que afecta a la economía financiera para abordar luego lo relativo a la economía real.

En lo que al mundo financiero atañe, los primeros signos de crisis se presentaron en la bolsa durante el mes de agosto. Era el típico contagio del comportamiento de la bolsa norteamericana. Sin embargo, a España apenas habían llegado los bonos americanos de los fondos de alto riesgo: por eso inicialmente no hubo problemas para las instituciones financieras. La supervisión del Banco de España (BE) 
y las costumbres habituales de las entidades financieras españolas impidieron que prácticas peligrosas, como las hipotecas "basura", se extendieran en nuestro país ${ }^{14}$. Por esta razón apenas creció la morosidad. Sí hubo algún problema de liquidez, pero sin que llegara a afectar profundamente a los mercados financieros.

Posteriormente, los bancos españoles siguieron manteniendo la solvencia y no tuvieron que acudir a créditos de emergencia del $\mathrm{BCE}$; pero esto no impide que se pueda producir algún "contagio", como se ha observado recientemente en el caso del Banco de Santander. Todo ello permitió un crecimiento de los resultados de los bancos en el tercer trimestre. Dado el peso de los grandes bancos en el IBEX ${ }^{15}$, las cotizaciones bursátiles han ido en aumento, con un comportamiento más favorable que el de los mercados de otros países. Lo que no ha cesado de aumentar en los últimos meses ha sido la volatilidad. Un dato importante es que el volumen de negocio de la bolsa en noviembre ha caído un 13,2\% sobre el mes anterior. Sin embargo, el conjunto del año ha sido muy positivo, con un aumento de dicho volumen de negociación de un 50\% sobre el año anterior. La incertidumbre aparece también en las opiniones de los expertos, mientras que algunos recomiendan la inversión en bolsa, otros aconsejan vender los valores y mantener liquidez ¡No se aclaran!

Por otra parte, se ha producido un endurecimiento de las condiciones de los créditos, sobre todo de los hipotecarios, y se han frenado los créditos a los promotores inmobiliarios. Y ha tenido sus efectos, porque el crédito hipotecario creció en septiembre de 2007 un 17,6\%, mientras que en septiembre de 2006 lo había hecho un $24,7 \%$. Incluso se ha temido que la restricción del crédito fuera demasiado lejos, lo que motivó que el propio Presidente del Gobierno pidiera en un momento a la banca que "reabran el crédito inmobiliario", opinión sin duda un poco arriesgada. Más prudente parece la opinión del Presidente de la Confederación de Cajas de Ahorros que les ha aconsejado que frenen la concesión de créditos.

Un aspecto positivo es que las empresas han vuelto emitir valores de renta fija y los grandes bancos han emitido cédulas hipotecarias. Hay que dejar constancia también de que se ha producido una guerra de pasivos. También los fondos de

\footnotetext{
14 Un ejemplo: el BE ha recomendado, con gran énfasis, a las entidades que no inviertan en valores de los que no conozcan su respaldo o contenido. No hay que olvidar que el BCE realiza labores de supervisión. En Europa, cada país tiene uno o varios supervisores que con frecuencia son los propios bancos centrales.

${ }^{15}$ El IBEX es el índice de las cotizaciones de bolsa de las 35 sociedades más importantes del mercado bursátil español.
} 
inversión se han encontrado con problemas, sobre todo la reducción del patrimonio, lo que no les ha impedido alcanzar una buena rentabilidad todavía en el mes de octubre. Por su parte, los "hedge funds" mantienen su actividad en el mercado español.

Todo esto representa unos cambios importantes del funcionamiento, e incluso de la estructura, del sistema financiero en España; la adaptación a esta nueva situación requerirá tiempo y causará problemas. Por otra parte, las empresas de calificación valoran actualmente de forma positiva la solvencia de las empresas del IBEX. Consideremos que estamos en un momento de incertidumbre; frente a esta opinión positiva, tenemos la postura de algunos fondos de inversión extranjeros que han retirado su confianza en las inmobiliarias, las constructoras e incluso los bancos españoles, debido a un fuerte pesimismo sobre el futuro de la economía española.

Si de la economía financiera pasamos a la economía real de nuestro país, lo primero que hay que dejar sentado es que partíamos de una mejor situación que otros países de la eurozona; el dato más relevante es que el crecimiento del Producto Interior Bruto español era, y sigue siendo, superior al de dicha zona. Sin embargo, pronto han aparecido algunos síntomas negativos:

- El primero ha sido el debilitamiento de la actividad constructora: si la participación media para el periodo 2000-2006 de este sector en el PIB fue de un 16,5\%, en el primer trimestre de 2007 había caído a un $9,3 \%$.

- El fortalecimiento del euro ha dejado sentir sus efectos sobre nuestras exportaciones ${ }^{16}$, aunque éstos hayan sido menores que en otros países europeos.

- La financiación se ha encarecido.

- La subida de precio del petróleo y el elevado endeudamiento de las familias son factores de carácter muy distinto, pero ambos alimentan los riesgos inflacionistas.

Todo esto hay que enmarcarlo, además, en el contexto de un menor crecimiento mundial. Ante este conjunto de hechos no es aventurado adelantar que el crecimiento en 2008 será menor que el previsto en los Presupuestos Generales del Estado, aunque podemos esperar que seguirá siendo superior a la media europea (según la OCDE,

\footnotetext{
${ }^{16}$ Un ejemplo: el grupo aeroespacial EADS ha decidido deslocalizar algunas de sus plantas en España a países de la zona del dólar para que la fortaleza del euro no perjudique sus exportaciones.
} 
será de un 2,5\% en España, mientras que el Vicepresidente Solbes mantiene que será superior al 3\%, admitiendo, sin embargo, que el crecimiento será inferior a lo que aparece en los presupuestos). De momento tenemos el dato correspondiente al tercer trimestre de 2007, que arroja un crecimiento del 3,8\%, inferior al de los trimestres anteriores; al mantenimiento de un cierto ritmo de crecimiento ha podido contribuir el hecho de que los resultados de las empresas del IBEX han sido muy buenos durante ese tercer trimestre ${ }^{17}$. Las previsiones a partir del cuarto trimestre de 2007 son más pesimistas, al menos en opinión de algunos expertos.

Podemos concluir que la economía española no podrá librarse de los problemas generados por la crisis que estamos analizando. Pero hay que añadir que la situación será más llevadera que en Estados Unidos, e incluso que en otros países europeos.

\section{Conclusiones: lecciones aprendidas y reflexiones éticas}

Nuestra preocupación última al redactar estas páginas no era sólo comprender el alcance y las causas de la reciente crisis, sino tomar postura ante ella. Por eso estas conclusiones que siguen hemos pensado que podíamos redactarlas en forma de consideraciones éticas. Lo hacemos con la conciencia de que no todos nuestros lectores las compartirán, porque en nuestras sociedades no es frecuente el consenso ético sobre la mayoría de las cuestiones. Y la economía no es ajena a esta diversidad de enfoques y posturas. Queremos, por tanto, que las consideraciones que siguen contribuyan a enriquecer el debate, poniendo de manifiesto que, detrás del discurso más técnico que analiza la compleja realidad económica, se esconden aspectos éticos que en modo alguno pueden reducirse a razonamientos de expertos en economía y finanzas.

El punto de partida de la crisis se localiza en el sector de la construcción de viviendas. Estamos pues en un terreno esencial para la vida de las sociedades porque afecta a un bien estrechamente relacionado con uno de los derechos humanos más fundamentales. Que dicho bien pueda ser suministrado a todos los ciudadanos en condiciones adecuadas de calidad y precio es, en principio, una cuestión económica, pero su tutela ha de ser tarea prioritaria de todo gobierno y de toda gestión política ${ }^{18}$.

\footnotetext{
${ }^{17}$ Otras empresas tienen peores resultados; así han tenido problemas, entre otras, la sociedad de valores GAESCO y la inmobiliaria catalana HABITAT, pero quizás estos sean casos particulares.

${ }^{18}$ De este tema nos ocupamos en nuestra reflexión editorial: CONSEJO DE REDACCIÓN (2005), "La vivienda
} 
Para que el sector funcione con la fluidez que necesita es preciso que cuente con un sistema de financiación adecuado. La inversión exigida al constructor no puede ser recuperada en un plazo breve de tiempo, lo que justifica la puesta a punto de instrumentos de financiación a largo plazo. Una vez más se muestra en este caso que la economía real (la producción de viviendas) necesita apoyarse en la economía financiera. Más aún, la economía financiera encuentra su última razón de ser en contribuir al bienestar social como complemento de la actividad económica de producción de bienes y servicios.

Sin embargo el caso que venimos analizando muestra, como ocurre con otros muchos, que los aspectos financieros se desarrollan de tal manera y con tal complejidad que el sector de la economía real que está en el origen pasa a un muy segundo término. El recorrido que hemos hecho sobre los aspectos de la crisis nos ha llevado a olvidarnos muy pronto de la vivienda para centrar toda la atención en los mercados financieros vinculados al sector de la construcción. Es cierto que esta complejidad de los instrumentos financieros hoy disponibles da fluidez a la economía. Pero llega un momento en que las operaciones financieras adquieren tal protagonismo que llegan a ser totalmente autónomas: es decir, encuentran en ellas mismas toda su razón de ser.

Es aquí donde el interrogante ético se hace más acuciante: ¿̇no hemos invertido los términos convirtiendo los medios en fines? Si la economía financiera es un complemento de la economía real, ¿̇no estamos asistiendo a un proceso a través del cual ésta última termina por quedar totalmente sometida a los dictados y exigencias de aquélla? La relación entre economía real y economía financiera es, a nuestro entender, uno de los grandes retos éticos del mundo actual. Es inquietante contemplar cómo se ha desarrollado el mundo de las finanzas, qué grados de complejidad ha alcanzado, con qué autonomía se mueve y cómo todo ello afecta a la economía real y a la producción de bienes y servicios, muchas veces imprescindibles para el bienestar de las sociedades.

Cuestionar esta nueva relación entre economía financiera y economía real, que es el resultado de un proceso espontáneo desarrollado a lo largo de casi un siglo, es cuestionar que la libertad individual y los intereses particulares de los agentes económicos deba ser el motor esencial de la economía. Hoy no está de moda hablar de intervención de los poderes públicos en la marcha de la economía. Y existen

en España: un mercado imperfecto e injusto", Revista de Fomento Social, $\mathrm{n}^{\circ} 240$, octubre-diciembre, pp. 537-559. Aunque referido al caso español, ese editorial hacía también unas valoraciones éticopolíticas que serían aplicables en el contexto de esta reflexión. 
razones históricas que explican estas resistencias. Pero no nos parecen suficientes para negar todo tipo de actuación pública.

Más arriba hemos tenido ocasión de ver cuán tímida ha sido la intervención de los organismos públicos en el control de la crisis. Y hemos visto también cómo esas tímidas intervenciones han servido en algunos países para reducir los efectos de la crisis. ¿Por qué no reconocer que la experiencia de los mercados financieros, que son aquéllos donde las trabas normativas son menores, está invitando a revisar esa confianza tan absoluta en que el mercado libre es el que mejor alcanza los objetivos económicos? El caso de los créditos hipotecarios de alto riesgo no es el primero que en los últimos años ha producido una verdadera conmoción en la economía mundial. No podemos decir, por tanto, que ha sido un fenómeno aislado. Es cierto que cada crisis tiene su propio perfil. Pero $\dot{2}^{\text {no }}$ existe un punto común a todas ellas, que es la excesiva libertad en los mercados financieros y los movimientos irracionales que se producen en ellos, desproporcionados a las causas que los provocan?19

Todo esto adquiere una configuración nueva en el marco de la globalización. Y sabemos que la economía financiera es uno de los factores que más ha contribuido a acelerar los procesos globalizadores. Esto significa que la exigencia de intervención de los poderes públicos en la economía, que tradicionalmente se circunscribía al ámbito de cada Estado, hoy se plantea ya en términos planetarios. Curiosamente este discurso sí se está poniendo de moda. Hablar de "gobernanza mundial" es frecuente hoy y no faltan las propuestas en este sentido, a comenzar por los intentos de dotar a la Organización de las Naciones Unidas de una estructura más adecuada al escenario político actual.

Entre las tareas relacionadas con un nuevo orden económico mundial habría que mencionar la revisión del sistema monetario internacional. El actual está cargado de contradicciones: por una parte, refleja demasiado el escenario político y económico de finales de la segunda guerra mundial, que tiene ya poco que ver con el del siglo XXI; por otra parte, se ha ido deteriorando por las mismas dificultades que ha ido encontrando en su funcionamiento, de forma que algunos de los compromisos

\footnotetext{
${ }^{19}$ Conviene recordar tres fenómenos de años recientes: los problemas bursátiles de 1987, la crisis de cobertura del LONG-TERM CAPITAL MANAGEMENT en 1998, y la llamada "burbuja tecanológica" de 2000-2001; en todos ellos la innovación financiera en USA provocó unas crisis que obligaron a intervenir a la Reserva Federal. ¿̇No se ha aprendido nada del pasado? estar sometidos a las imprudencias de los financieros que terminan por afectar a la economía real en todo el mundo?
} 
que lo justificaban hace tiempo que dejaron de tener vigencia. Es cierto que, si se mantiene, es porque no se ve con qué sustituirlo. Pero esta dificultad tan real no puede llevarnos a una resignación definitiva, porque su falta de adecuación a las circunstancias de nuestro mundo es cada vez mayor.

Aunque pueda sonar a tópico, no podemos dejar de recordar una vez más que la economía tiene que estar al servicio de la persona humana, de toda la persona en sus diferentes dimensiones y de todas las personas sin discriminaciones. Subrayarlo al final de estas reflexiones ayuda a relativizar también el tema del crecimiento económico: es cierto que el crecimiento puede repercutir en una mejora del bienestar de todos, pero no es automática la relación de causa/efecto: es decir, tampoco puede dejarse al juego del libre mercado. En términos clásicos, habría que decir que el crecimiento es un objetivo intermedio, no final: por eso debe estar orientado a otro objetivo último, que no puede ser sino el acceso de todos a los frutos de ese crecimiento. Es demasiado frecuente el discurso de economistas y políticos que da por hecho que el crecimiento sin más es un bien para todos.

No quisiéramos que estas consideraciones finales sonasen a una ingenua confesión de confianza en la capacidad de los poderes públicos para conducir la economía al servicio de la sociedad toda. La experiencia histórica no abona esta confianza. Pero la alternativa de encomendarlo todo al mercado no nos parece correcta, porque implica reconocer que los intereses generales de la sociedad no existen o no exigen una tutela especial. Estamos convencidos de que existen: hay que formularlos y arbitrar estrategias para hacerlos realidad. Esta es tarea de la política. Desgraciadamente no corren vientos que favorezcan un aprecio social de la actividad política. ¿No es éste en el fondo el "handicap" principal para un funcionamiento equilibrado de la economía? Pero sin duda éste es un tema que desborda completamente las pretensiones de estas páginas. 